\title{
Rancang Bangun Alat Screw Extruder Untuk Pembuatan Papan Partikel Campuran Tandan Kosong Kelapa Sawit dan Plastik LDPE
}

\author{
Dytha Florenza* $^{* 1}$, Anerasari Meidinariasty ${ }^{2}$, Erwana Dewi ${ }^{3}$ \\ ${ }^{1,2,3}$ Program Studi Teknologi Kimia Industri, Jurusan Teknik Kimia, \\ Politeknik Negeri Sriwijaya, Indonesia. \\ Email: 1dythaflorenza@gmail.com
}

\begin{abstract}
Abstrak
Screw Extruder merupakan mesin dengan penggerak motor DC dengan pemanas berupa band heater sebagai elemen utama dengan jenis plastic yang akan dilelehkan. Penelitian ini bertujuan untuk membuat alat screw extruder untuk pencampuran serbuk tandan kosong kelapa sawit dan plastik Low Density Polyethylene (LDPE) menjadi papan partikel ukuran 20x10 yang memenuhi SNI 03-2015-2006 untuk pelapis dinding ruangan. Percobaaan dilakukan dengan tiga tahapan proses yaitu pre-treatment tandan kosong kelapa sawit, tahap pembuatan papan partikel dengan menggunakan alat screw extruder, dan tahap analisa papan partikel yang dihasilkan. Parameter yang diukur ialah kerapatan, kadar air, penambahan tebal, dan daya serap air dari papan partikel yang dihasilkan dengan variasi komposisi bahan TKKS:LDPE 20:80, 25:75, 30:70, 35:75, 40:60, dan variasi suhu extruder $250^{\circ} \mathrm{C}, 270^{\circ} \mathrm{C}$, dan $290^{\circ} \mathrm{C}$ dengan putaran screw tetap sebesar $20 \mathrm{rpm}$. Perancangan alat screw extruder ini memiliki kapasitas maksimal $19 \mathrm{~kg} / \mathrm{jam}$ dengan putaran screw maksimal $100 \mathrm{rpm}$. Komposisi TKKS:LDPE 20:80 dengan suhu extruder $290^{\circ} \mathrm{C}$ menghasilkan papan partikel dengan nilai kerapatan sebesar $0,75 \mathrm{gr} / \mathrm{cm}^{3}$ dengan kadar air minimum $0,11 \%$, daya serap air minimum $13,04 \%$, dan penambahan tebal minimum sebesar $3,05 \%$. Dari variasi suhu extruder $250^{\circ} \mathrm{C}, 270^{\circ} \mathrm{C}$, dan $290^{\circ} \mathrm{C}$ yang telah dilakukan pada pembuatan papan partikel, didapatkan kondisi optimum yaitu pada suhu extruder $290^{\circ} \mathrm{C}$ dan kondisi optimum variasi komposisi TKKS:LDPE adalah sebesar 20:80. Papan partikel yang dihasilkan dari alat screw extruder telah memenuhi SNI 03-2015-2006 dengan kondisi optimum suhu ektruder $290^{\circ} \mathrm{C}$ dan kondidi optimum perban komposisi TKKS:LDPE adalah 20:80.
\end{abstract}

Kata kunci: LDPE, papan partikel, screw extruder, TKKS.

\section{Design Of Screw Extruder for Manufacturing Particle Board Mixed Empty Fruit Bunches and LDPE}

\begin{abstract}
Screw Extruder is a machine with a DC motor drive with a heater in the form of a band heater as the main element with the type of plastic to be melted. This study aims to make a screw extruder tool for mixing oil palm empty fruit bunches powder and Low Density Polyethylene (LDPE) plastic into $20 x 10$ particle board that meets SNI 03-2015-2006 for room wall coatings. The experiment was carried out with three stages of the process, namely pre-treatment of empty oil palm fruit bunches, the stage of making particle board using a screw extruder, and the analysis stage of the resulting particle board. The parameters measured were density, moisture content, thickness addition, and water absorption from particleboard produced with variations in the composition of EFB: LDPE 20:80, 25:75, 30:70, 35:75, 40:60, and variations extruder temperatures of $250^{\circ} \mathrm{C}, 270^{\circ} \mathrm{C}$, and $290^{\circ} \mathrm{C}$ with a fixed screw rotation of $20 \mathrm{rpm}$. The design of this screw extruder has a maximum capacity of 19 $\mathrm{kg} / \mathrm{hour}$ with a maximum screw rotation of 100 rpm. The composition of OPEFB: LDPE 20:80 with an extruder temperature of $290^{\circ} \mathrm{C}$ produces particleboard with a density value of $0.75 \mathrm{gr} / \mathrm{cm} 3$ with a minimum moisture content of $0.11 \%$, a minimum water absorption capacity of $13.04 \%$, and a minimum thickness addition of 3.05 $\%$. From the variations in extruder temperatures of $250^{\circ} \mathrm{C}, 270^{\circ} \mathrm{C}$, and $290^{\circ} \mathrm{C}$ that have been carried out in the manufacture of particleboard, the optimum conditions were obtained at the extruder temperature of $290^{\circ} \mathrm{C}$ and the optimum conditions for variations in the composition of EFB: LDPE was 20:80. The particleboard produced from the screw extruder has complied with SNI 03-2015-2006 with the optimum condition of the extruder temperature of $290^{\circ} \mathrm{C}$ and the optimum condition of the bandage composition of OPEFB: LDPE is 20:80.
\end{abstract}

Keywords: $E F B, L D P E$, particle board, screw extruder. 


\section{PENDAHULUAN}

Dalam upaya alternatif untuk memenuhi kebutuhan bahan baku pada industri perkayuan, salah satunya adalah pemanfaatan teknologi papan yang menggunakan bahan baku selain kayu. Papan partikel merupakan papan komposit atau panel kayu yang terbuat dari partikel kayu atau bahan berlignoselulosa lainnya yang diikat dengan perekat sintetis atau perekat lainnya serta dikempa dengan kempa panas. Salah satu material bukan kayu dapat dijadikan sebagai bahan baku pembuatan papan yaitu tandan kosong kelapa sawit yang memiliki kandungan lignoselulosa yaitu memiliki kandungan lignin dan selulosa. Dalam pembuatan papan partikel juga dibutuhkan perekat. Salah satu perekat yang sangat mudah dijumpai adalah plastic terutama jenis limbah plastik Low Density Polyethylene (LDPE) yang berasal dari plastik pembungkus.

Papan partikel dapat dibuat dari serat tandan kosong kelapa sawit (TKKS) dan plastik sebagai perekat dengan menggunakan alat screw extruder. Screw extruder merupakan mesin dengan penggerak motor DC yang bekerja dengan elemen utama pemanas berupa band heater dengan jenis material plastik yang akan dilelehkan. Salah satu keunggulan mesin ini adalah proses yang terjadi sifatnya kontinyu sehingga secara langsung dapat dilakukan proses pencetakan. Screw extruder dirancang dengan mengontrol kapasitas produksi, temperatur, jenis pengadukan, dan waktu operasi agar rancang alat ini mampu bekerja secara efisien. Rancang bangun alat screw extruder diharapkan dapat mengurangi cost produksi papan partikel konvensional dengan memodifikasi bahan perekat dan bahan isian dengan pemanfaatan limbah dalam kehidupan sehari hari.

Penelitian rancang bangun pembuatan alat papan serat dengan metode Screw Exturder mengacu pada penelitian Satito (2016) tentang pembuatan papan partikel dengan alat Screw Extruder berkapasitas $50 \mathrm{~kg} / \mathrm{jam}$ menghasilkan papan kayu berkualitas baik, namun perancangan alat screw extruder masih menggunakan sistem kontrol manual dan belum menggunakan sistem insulasi pada barrel yang berfungsi untuk meminimalkan heatloss selama operasi dan melindungi operator dari kontak panas langsung. Alat tersebut juga masih menggunakan unit penggerak transmisi pulley dan belt [1]. Penggunaan transmisi pulley dan belt memiliki kelemahan diantaranya kapasitas daya yang dapat ditransmisikan terbatas dan rasio kecepatan terbatas. Menindaklanjuti penelitian Satito (2016), dilakukan penelitan rancang bangun alat screw extruder dengan memodifikasi insulasi pada barrel dan penggunaan Inverter yang seringkali disebut Variable Speed Drive (VSD) atau Variable Frequency Drive (VFD) pada motor penggerak. Penggunaan VFD pada motor listrik dapat menyesuaikan kecepatan screw sesuai dengan yang dibutuhkan dalam proses ekstrusi sehingga mencegah terjadinya penggunaan energi yang sia-sia dan mampu mengurangi biaya listrik. Hal ini diharapkan mampu meningkatkan efektivitas alat screw extruder dalam memproduksi papan serat berkerapatan sedang.

Tujuan dari penelitian ini adalah membuat alat Screw Extruder untuk pencampuran serbuk TKKS dengan plastik LDPE menjadi papan partikel ukuran 20 x $10 \mathrm{~cm}$ yang memenuhi SNI 03-2015-2006 untuk pelapis dinding ruangan. Dimana Permasalahan pada penelitian ini yaitu bagaimana kinerja alat screw extruder serta cara mengoperasikannya secara efektif dan efisien dalam teknologi pembuatan papan partikel dengan meninjau kinerja alat screw extruder berdasarkan pengaruh komposisi bahan baku dan suhu extruder, sehingga produk papan partikel yang memenuhi standar SNI 03-2105-2006 yang dapat digunakan untuk papan pelapis dinding ruangan.

\subsection{Screw Extruder}

Screw extruder merupakan alat pencampur di industri plastik. Alat screw extruder merupakan mesin dengan penggerak motor DC. Mesin bekerja dengan elemen utama pemanas berupa band heater dengan jenis material plastik yang akan dilelehkan. Pada alat screw extruder terjadi proses ekstrusi plastik yang dilakukan dengan menekan bahan dasar plastik agar mengalir melalui lubang pada cetakan menghasilkan produk yang bentuknya ditentukan oleh bentuk lubang cetakan yang berbentuk piringan atau silinder pada bagian akhir mesin ekstrusi. Cetakan atau die berfungsi sebagai pembentuk atau pencetak bahan setelah diolah di dalam mesin ekstrusi ke bentuk yang diinginkan. Mesin ekstrusi memiliki bagian yang bernama extruder. Extruder memiliki fungsi sebagai pelebur plastik yang nantinya akan diproses melalui zona pemanas yang memiliki suhu berbedabeda dan akan didorong keluar oleh screw conveyor hingga sampai pada bagian cetakan [2].

\subsection{Papan Artikel}

Papan partikel merupakan salah satu jenis produk komposit atau panel kayu yang terbuat dari partikelpartikel kayu atau bahan berlignoselulosa lainnya, yang diikat dengan perekat sintetis atau bahan pengikat lain dan dikempa dengan panas [3]. Papan partikel umumnya berbentuk datar dengan ukuran relatif panjang, lebar, dan tipis dan dengan ukuran ideal partikel untuk papan partikel adalah 0,5 - 1 in dan tebal 0,010-0,015 in [4] 


\subsection{Tandan Kosong Kelapa Sawit (TKKS)}

Tandan kosong sawit merupakan limbah padat dari industri sawit yang jumlahnya cukup besar dan sampai saat ini pemanfaatannya masih terbatas. Pemilihan tandan kosong kelapa sawit (TKKS) sebagai bahan baku papan partikel, karena berdasarkan dari segi sifat fisika dan kimia tandan kosong kelapa sawit sangat potensial untuk pembuatan papan partikel karena mengandung komposisi kimia diantaranya adalah lignin $(20,62)$, hemiselulosa $(22,84 \%)$, selulosa $(49,95 \%)$, dan zat ekstraktif $(3,74 \%)$ [5]. Kandungan serat tandan kosong kelapa sawit $72,67 \%$ dan ukuran partikelnya yang sesuai dengan persyaratan bahan baku papan partikel [6]. Alasan lain pemilihan tandan kosong kelapa sawit sebagai bahan baku papan partikel, karena potensi kebun kelapa sawit banyak terdapat di Indonesia baik milik pemerintah, dan swasta ataupun rakyat, serta peningkatan produksi kelapa sawit akan meningkatkan limbah padat berupa tandan kosong, serat peresan buah, pelepah dan sabut kelapa sawit, sehingga berpotensi untuk digunakan sebagai bahan baku papan partikel dengan jumlahnya cukup banyak.

\subsection{Plastik Low Density Polyethylene (LDPE)}

Plastik merupakan bahan polimer kimia yang banyak digunakan dalam kehidupan manusia. Hampir setiap produk menggunakan plastik baik sebagai kemasan atau bahan dasar karena plastik mempunyai keunggulan seperti ringan, kuat, transparan, tahan air serta harganya relatif murah dan terjangkau oleh semua kalangan masyarakat. Polyethylene (PE) adalah salah satu jenis plastik yang paling banyak dipakai dalam kehidupan sehari-hari seperti kantong plastik yang terbuat dari jenis Low Density Polyethylene (LDPE) [7]. LDPE berasal dari gabungan monomer jenis ethylene $\mathrm{C}_{2} \mathrm{H}_{4}$ yang mengalami proses polimerisasi dengan tekanan tinggi dengan penambahan inisiator radikal bebas. LDPE memiliki kristalinitas yang lebih rendah dibandingkan dengan HDPE karena kemampuannya yang lebih rendah pada saat packing. LDPE memiliki titik leleh $105^{\circ} \mathrm{C}-115^{\circ} \mathrm{C}$, derajat kristalinitas $65 \%$, densitas $0,91-0,92 \mathrm{gr} / \mathrm{cm} 3$, titik lunak $105^{\circ} \mathrm{C}$, kuat tekan $144 \mathrm{kgf} / \mathrm{cm}^{2}$, perpanjangan $500 \%$ dan tensile strength $11-27 \mathrm{Mpa}[8]$.

\subsection{Natrium Hidroksida $(\mathrm{NaOH})$}

$\mathrm{NaOH}$ memiliki berat molekul $40 \mathrm{~g} / \mathrm{mol}$, larut dalam air, meleleh pada $323^{\circ} \mathrm{C}$, mendidih pada temperatur $1388^{\circ} \mathrm{C}$, dan specific grafity 2,13 . $\mathrm{NaOH}$ merupakan larutan basa yang tergolong mudah larut dalam air dan termasuk basa kuat yang dapat terionisasi dengan sempurna. Basa adalah zat yang dalam air menghasilkan ion $\mathrm{OH}$ negatif dan ion positif. Larutan basa memiliki rasa pahit, dan jika mengenai tangan terasa licin (seperti sabun). Sifat licin terhadap kulit itu disebut sifat kaustik basa. Perlakuan $\mathrm{NaOH}$ ini bertujuan untuk melarutkan lapisan yang menyerupai lilin di permukaan serat, lignin, dan kotoran lainnya. Dengan hilangnya lapisan lilin ini maka ikatan antara serat dan matriks menjadi lebih kuat, sehingga kekuatan tarik komposit menjadi lebih tinggi. Kegunaan $\mathrm{NaOH}$ adalah untuk menghilangkan lignin, silika, pati, dan zat ekstraktif dari serat agar memiliki impregnasi lebih baik antara serat dan matriks dan meningkatkan kekasaran permukaan serat agar dapat terjadi interaksi yang lebih baik yang menjadi tujuan utama pengolahan secara kimia [9].

\section{METODE PENELITIAN}

Penelitian ini menggunakan metode rancang bangun dan eksperimen, dilakukan selama 4 bulan. Metode rancang bangun dilakukan untuk perancangan dan pembuatan screw extruder. Metode eksperimen dilakukan untuk mengetahui kinerja mesin screw extruder pada proses pembuatan papan partikel campuran tandan kosong kelapa sawit dan plastik low density polyethylene (LDPE).

\subsection{Pendekatan Desain Struktural}

Desain struktural adalah desain yang mengandung unsur-unsur seperti garis, bentuk, dan ukuran dalam suatu alat. Desain tersebut dapat berbentuk alat dalam tiga dimensi maupun dalam bentuk gambar dari suatu alat. Desain struktural menunjukkan bagaimana suatu alat itu dikonstruksikan dan bagaimana alat tersebut memenuhi fungsinya. Pendekatan desain struktural menjelaskan struktur secara detail dari suatu alat, baik dari material, ukuran maupun proses pembuatannya yang dapat diamati pada Gambar 1 .

\subsection{Prosedur Percobaan}

\subsubsection{Waktu dan Tempat}

Pelaksanaan penelitian perancangan alat Screw Extruder pembuatan papan partikel berbahan TKKS dengan perekat plastik LDPE, dilakukan selama 4 bulan yaitu dimulai pada bulan Maret - Juli 2021 di Laboratorium 
Jurusan Teknik Kimia Politeknik Negeri Sriwijaya.

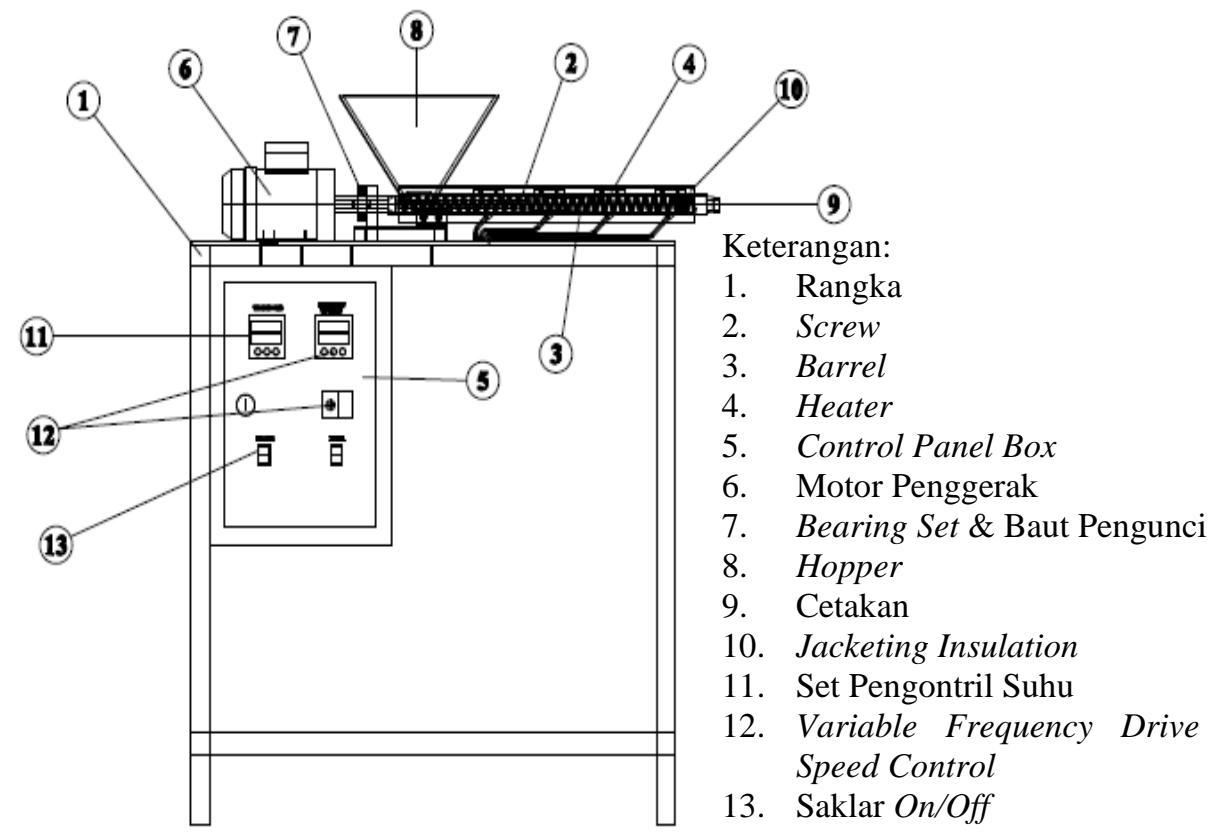

Gambar 1. Screw Extruder

\subsubsection{Alat dan Bahan}

Adapun alat dan untuk pembuatan alat screw extruder, diantaranya adalah mesin las, gerinda, bor, obeng, tang, palu, kunci 10, kunci 12, kunci 14, kunci inggris, penggaris siku, meteran, kuas, pensil, gunting, dan solder. Adapun bahan untuk pembuatan alat screw extruder, diantaranya adalah rangka (besi hollow), barrel, screw, hopper, band heater, motor induksi 2hp, gearbox transmisi, Mechanical Adjustable Speed Drive (Rantai dan Gear), diehead (kepala cetakan), cetakan, plat aluminium, Insulation Jacket (Rockwool), bearing set, control panel, Variable Speed Drive (VSD), tachometer digital, sensor termokopel, thermocontrol REX-C100, kabel, saklar on/off, potensio, papan tripleks, baut 12, baut 14, sekrup, cat, thinner, amplas, lem kabel, dan timah.

Adapun alat yang digunakan dalam pembuatan papan partikel ini adalah Gelas ukur, neraca analitik, wadah, stopwatch, kunci 10, kunci 12, kunci 14, tang, dan lap kain. Bahan baku yang digunakan dalam penelitia ini adalah tandan kosong kelapa sawit (TKKS), plastik low density polyethylene (LDPE), Natrium Hidroksida $(\mathrm{NaOH})$, dan aquadest.

\subsubsection{Variabel Penelitian}

Variabel bebas dalam penelitian ini adalah temperatur pemanasan $\left(250^{\circ} \mathrm{C}, 270^{\circ} \mathrm{C}\right.$, dan $\left.290^{\circ} \mathrm{C}\right)$ dan komposisi TKKS:LDPE (20:80, 25:75, 30:70, 35:75, dan 40:60). Variabel kontrol dalam penelitian ini adalah putaran Screw sebesar $20 \mathrm{rpm}$, total massa bahan baku $600 \mathrm{gr}$, konsentrasi $\mathrm{NaOH}$ untuk perendaman 6\%, dan waktu perendaman selama 30 menit. Variabel terikat dalam penelitian ini adalah kadar air papan partikel, kerapatan papan partikel, penambahan tebal papan partikel setelah perendaman air, dan daya serap air papan partikel.

\subsubsection{Pre-treatment Tandan Kosong Kelapa Sawit}

Tandan kosong kelapa sawit yang akan diolah diambil, dipotong- potong hingga berukuran $\pm 10 \mathrm{~cm}$, dicuci bersih dan ditiriskan. Perlakuan alkalisasi pada tandan kosong kelapa sawit dengan direndam larutan $\mathrm{NaOH} 6 \%$ selama 30 menit. Kemudian dibilas dengan air hingga $\mathrm{pH}$ 7-7,5. Setelah dibilas, tandan kosong kelapa sawit dikeringkan dibawah sinar matahari hingga kadar air $<5 \%$. Setelah dikeringkan, tandan kosong kelapa sawit di potong kecil hingga berukuran $\pm 0,5 \mathrm{~cm}$.

\subsubsection{Proses Pembuatan Alat Screw Extruder}

Kerangka alat dibuat seperti bentuk meja dengan ukuran $70 \mathrm{~cm} \mathrm{x} 40 \mathrm{~cm}$ x $70 \mathrm{~cm}$ sebagai tempat dudukan 
alat barrel, motor induksi, dan gearbox. Control panel diletakan di bagian depan dengan ukuran penyangga 45 $\mathrm{cm}$ x $30 \mathrm{~cm}$. Barrel dibuat menggunakan pipa stainless steel dengan diameter 1 inch dengan panjang 50 cm. 7,5 $\mathrm{cm}$. Band heater dengan diameter 1 inch sebanyak 4 buah yang kemudian dipasang pada bagian pengumpan (feed section), bagian penekan (compression section), bagian pengaduk (mixing section) dan bagian cetakan (die section). Gearbox dan motor induksi AC 1,5 kW diletakan pada dudukan yang telah dibuat sebelumnya dan dihubungkan dengan gear, rantai, dan shaft. Control panel box dipasang di bagian depan kerangka. Band heater dihubungkan motor induksi. Cetakan dibuat dengan ukuran $200 \mathrm{~mm}$ x $100 \mathrm{~mm}$ x $25 \mathrm{~mm}$ menyesuaikan dengan ukuran standar besi hollow dan diberikan dudukan agar bisa terhubung ke lubang die. Hopper dibuat dengan bentuk frustum pyramid dan dipasang pada dudukan barrel.

\subsubsection{Proses Pembuatan Papan Partikel}

Proses pembuatan papan partikel awali dengan mencampur TKKS dan LDPE dengan perbandingan (20:80, 25:75, 30:70, 35:75, dan 40:60) dengan total berat 600 gr. Campuran tersebut lalu dimasukkan ke alat screw extruder. Didalam alat screw extruder terjadi proses ekstrusi dimana LDPE akan melelh dan tercampur rata dengan TKKS. Setelah proses ekstrusi, campuran TKKS dan LDPE akan masuk ke cetakan berukuran $200 \mathrm{~mm} x$ $100 \mathrm{~mm}$ x $25 \mathrm{~mm}$. Kemudian cetakan dilepaskan dari alat dan didiamkan, selanjutnya cetakan dibuka dan dihasilkan produk papan partikel. Produk papan partikel yang dihasilkan didiamkan dahulu selama 1 hari sebelum dilakukan analisa.

\subsubsection{Tahap Analisa}

Tahap analisa bertujuan untuk mengetahui kualitas dan kelayakan papan partikel dari tandan kosong kelapa sawit (TKKS) dan plastik Low Density Polyethylene (LDPE) berdasarkan SNI 03-2105-2006. Tahap analisa yang dilakukan adalah analisa kadar air, kerapatan partikel, daya serap air, dan penambaha tebal setelah perendaman.

\section{HASIL DAN PEMBAHASAN}

Alat Screw Extruder yang telah dibuat dapat dilihat pada Gambar 2.

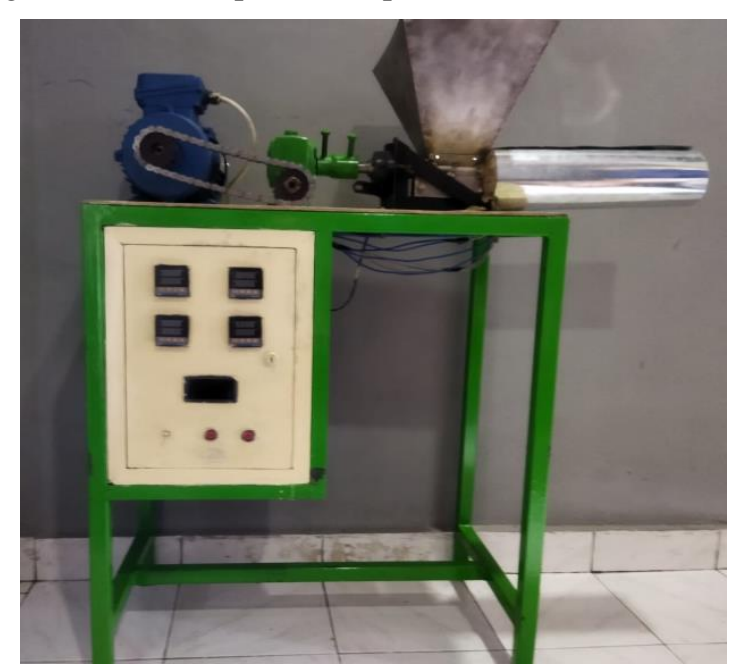

Gambar 2. Alat Screw Extruder

Alat Screw Extruder yang telah dibuat memiliki spesifikasi antara lain:
a. Kapasitas max
$: 19 \mathrm{~kg} / \mathrm{jam}$
b. Dimensi
c. Heater
d. Berat barrel
: $2 \mathrm{~m} \mathrm{x} 1 \mathrm{~m} \mathrm{x} 2 \mathrm{~m}$
e. Diameter Screw
: 4 buah, suhu max. $300^{\circ} \mathrm{C}$
f. Power $(\mathrm{kW})$
$: 2 \mathrm{~kg}$
$: 2,4 \mathrm{~cm}$
g. Tipe screw
: $1,5 \mathrm{~kW}$
: Single Screw

Produk papan partikel yang telah dihadilkan dapat dilihat pada gambar 3, 4, 5, 6, 7, 8, 9, dan 10 . 


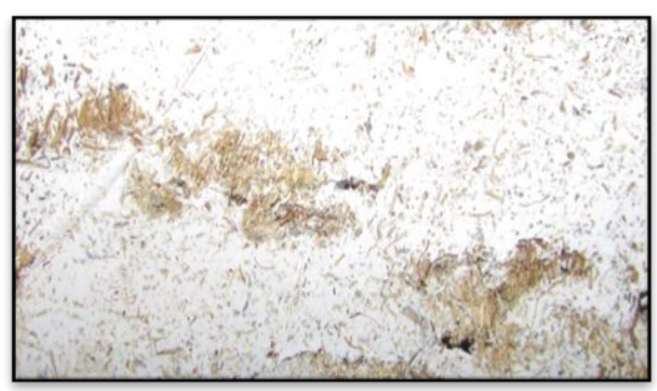

Gambar 3. Papan Partikel dengan komposisi TKKS:LDPE 20:80 dan suhu Extruder $250^{\circ} \mathrm{C}$

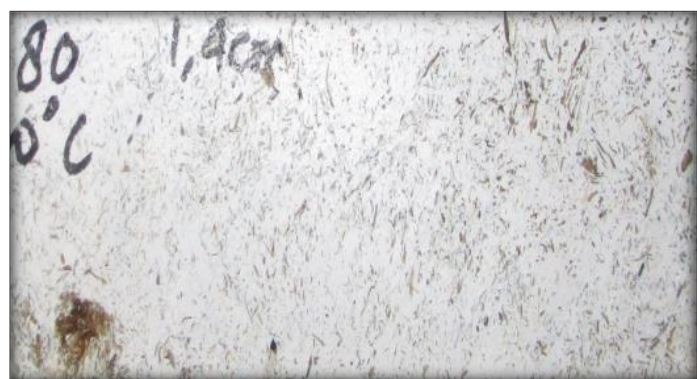

Gambar 4. Papan Partikel dengan komposisi TKKS:LDPE 20:80 dan suhu Extruder $270^{\circ} \mathrm{C}$

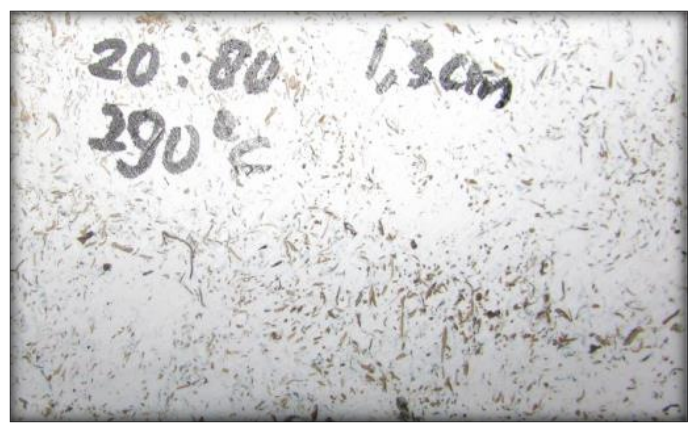

Gambar 5. Papan Partikel dengan komposisi TKKS:LDPE 20:80 dan suhu Extruder $290^{\circ} \mathrm{C}$

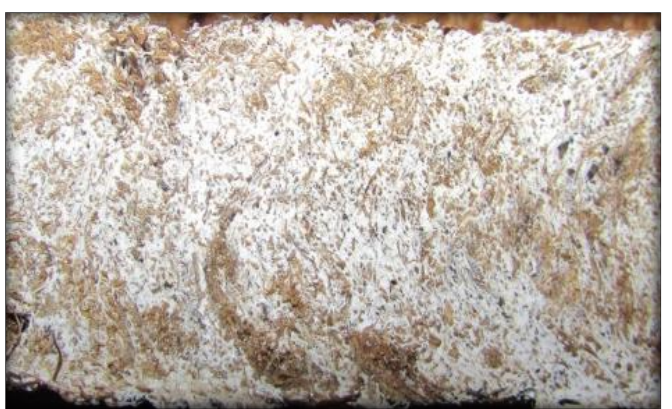

Gambar 6. Papan Partikel dengan komposisi TKKS:LDPE 25:75 dan suhu Extruder $290^{\circ} \mathrm{C}$

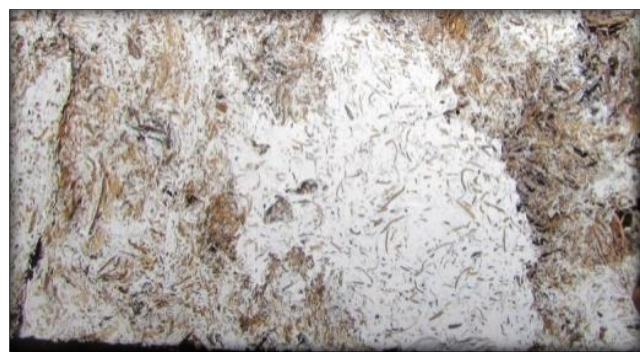

Gambar 7. Papan Partikel dengan komposisi TKKS:LDPE 30:70 dan suhu Extruder $290^{\circ} \mathrm{C}$ 408 


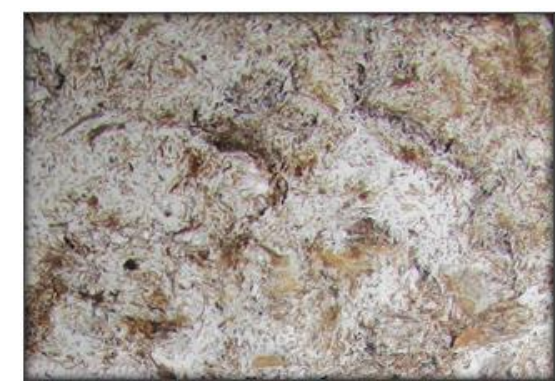

Gambar 8. Papan Partikel dengan komposisi TKKS:LDPE 35:65 dan suhu Extruder $290^{\circ} \mathrm{C}$

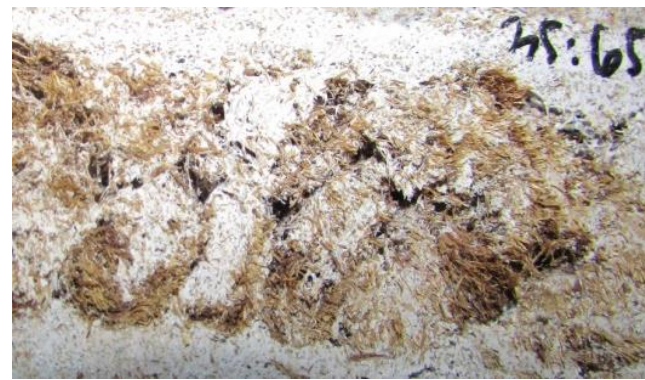

Gambar 9. Papan Partikel dengan komposisi TKKS:LDPE 35:65 dan suhu Extruder $270^{\circ} \mathrm{C}$

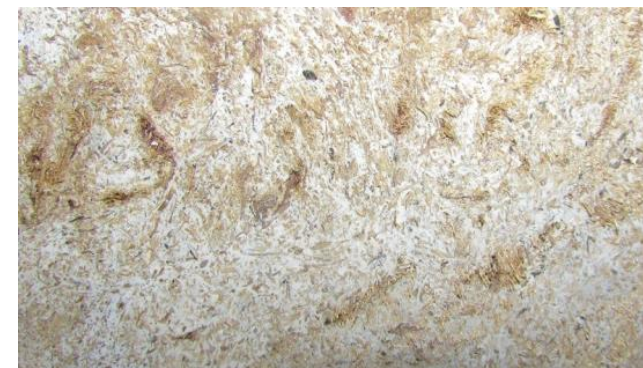

Gambar 10. Papan Partikel dengan komposisi TKKS:LDPE 40:60 dan suhu Extruder $290^{\circ} \mathrm{C}$

Berikut tabel rekapitulasi hasil analisa papan partikel dengan perbandingan komposisi sample TKKS:LDPE yaitu 20:80, 25:75, 30:70, 35:65, dan 40:60 serta suhu Extruder sebesar $250^{\circ} \mathrm{C}, 270^{\circ} \mathrm{C}$, dan $290^{\circ} \mathrm{C}$.

Tabel 1. Hasil Analisa Papan Partikel

\begin{tabular}{|c|c|c|c|c|c|}
\hline $\begin{array}{c}\text { Suhu Extruder } \\
\left({ }^{\circ} \mathrm{C}\right)\end{array}$ & $\begin{array}{c}\text { TKKS:LDPE } \\
(\%)\end{array}$ & $\begin{array}{c}\text { Kadar Air } \\
(\%)\end{array}$ & $\begin{array}{c}\text { Kerapatan } \\
\left(\mathrm{gr} / \mathrm{cm}^{3}\right)\end{array}$ & $\begin{array}{c}\text { Daya Serap Air } \\
(\%)\end{array}$ & $\begin{array}{c}\text { Penambahan Tebal } \\
(\%)\end{array}$ \\
\hline \multirow{5}{*}{250} & $20: 80$ & 0,21 & 0,74 & 13,11 & 5,02 \\
\hline & $25: 75$ & 0,27 & 0,73 & 18,62 & 7,66 \\
\hline & $30: 70$ & 0,47 & 0,72 & 25,77 & 9,96 \\
\hline & $35: 65$ & 0,57 & 0,71 & 29,21 & 10,89 \\
\hline & $40: 60$ & 0,69 & 0,71 & 32,72 & 11,97 \\
\hline \multirow{5}{*}{270} & $20: 80$ & 0,13 & 0,75 & 13,09 & 4,21 \\
\hline & $25: 75$ & 0,23 & 0,74 & 18,58 & 6,27 \\
\hline & $30: 70$ & 0,35 & 0,73 & 25,09 & 8,95 \\
\hline & $35: 65$ & 0,56 & 0,73 & 28,70 & 10,77 \\
\hline & 40:60 & 0,68 & 0,72 & 31,89 & 11,58 \\
\hline \multirow{5}{*}{290} & $20: 80$ & 0,11 & 0,75 & 13,04 & 3,05 \\
\hline & $25: 75$ & 0,22 & 0,75 & 18,48 & 5,38 \\
\hline & $30: 70$ & 0,28 & 0,74 & 23,29 & 8,14 \\
\hline & $35: 65$ & 0,54 & 0,73 & 27,32 & 10,30 \\
\hline & $40: 60$ & 0,64 & 0,73 & 31,52 & 11,11 \\
\hline \multicolumn{2}{|c|}{$\begin{array}{c}\text { Standar } \\
\text { SNI 03-2105-2006 }\end{array}$} & $\leq 14$ & $0,4-0,9$ & $\begin{array}{c}\text { Tidak } \\
\text { Disyaratkan }\end{array}$ & $\leq 12$ \\
\hline
\end{tabular}




\subsection{Analisa Kadar Air}

Berdasarkan tabel 1, nilai kadar air partikel yang dibuat secara keseluruhan telah memenuhi standar SNI 03-2105-2006 yang mensyaratkan nilai persentase kadar air papan partikel maksimal 14\%. Hasil analisa kadar air papan partikel dapat dilihat pada gambar 11.

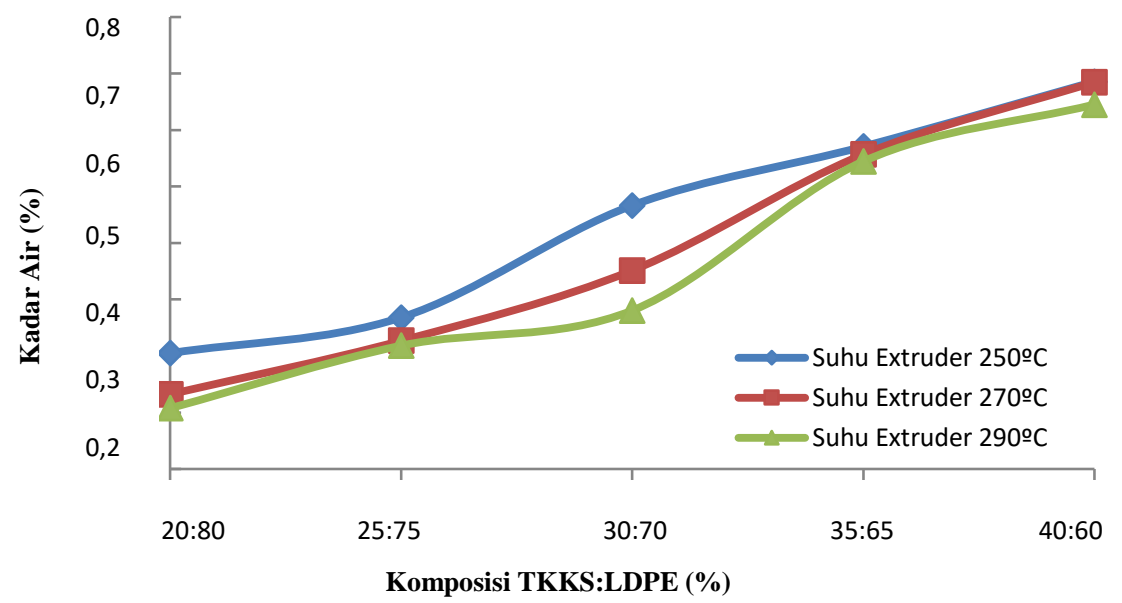

Gambar 11. Grafik Hubungan Antara Komposisi Bahan Baku dan Suhu Extruder Terhadap Kadar Air Papan Partikel

Berdasarkan gambar 11 terlihat bahwa semakin tinggi suhu extruder maka kadar air yang terkandung dalam papan partikel semakin berkurang. Nilai kadar air yang rendah ini merupakan akibat dari adanya perlakuan panas yang diterima saat proses ekstrusi sehingga plastik merekatkan serat TKKS dan juga menyebabkan serat TKKS tidak bebas menyerap air sebagai akibat adanya ikatan antara perekat dan serat TKKS. Peningkatan jumlah perekat pada pembuatan papan partikel sangat berpengaruh terhadap nilai kadar airnya. Suhu extruder yang lebih rendah mengakibatkan TKKS dan perekat plastik LDPE tidak terhomogenisasi dengan baik. Sehingga menyulitkan campuran untuk mengisi ruang cetakan. Berdasarkan Gambar 11 juga dapat dilihat bahwa semakin tinggi persentase serat TKKS dan semakin rendah persentase perekat plastik LDPE, maka persentase kadar air papan partikel akan semakin tinggi dan menyebabkan ikatan rekat menjadi semakin lemah. Hal ini disebabkan karena banyaknya rongga pada papan partikel yang tidak tertutupi oleh perekat plastik LDPE sehingga kemampuan menyerap air dari udara berkurang. nilai kadar air yang rendah disebabkan oleh jumlah perekat yang lebih banyak yang akan menutupi rongga sel TKKS pada papan partikel dengan sempurna sehingga tidak mudah terhidrolisis. Kadar air pada papan partikel dipengaruhi oleh nilai kerapatannya, papan partikel yang memiliki nilai kerapatan yang lebih tinggi mempunyai ikatan antar molekul partikel dengan molekul perekat yang lebih kuat sehingga molekul air sulit untuk mengisi rongga yang terdapat dalam proses pembuatan papan partikel karena rongga tersebut terisi dengan molekul perekat.

\subsection{Analisa Kerapatan Partikel}

Berdasarkan tabel 1, nilai kerapatan pada papan partikel yang dibuat secara keseluruhan telah memenuhi standar SNI 03-2105-2006 yaitu mensyaratkan nilai kerapatan pada papan papan partikel sebesar 0,4-0,9 g/cm ${ }^{3}$.

Pada gambar 12 yang dialurkan dari tabel 1 terlihat bahwa papan partikel yang memiliki nilai kerapatan tertinggi adalah papan partikel dengan perbandingan komposisi TKKS:LDPE sebesar 20:80 dengan Suhu Extruder sebesar $290^{\circ} \mathrm{C}$. Sedangkan untuk nilai kerapatan terendah yaitu pada papan partikel dengan perbandingan komposisi TKKS:LDPE sebesar 40:60 dengan Suhu Extruder $250^{\circ} \mathrm{C}$. Tinggi rendahnya suhu extruder sangat berpengaruh pada nilai kerapatan, dimana semakin tinggi suhu extruder maka campuran antara TKKS dan Perekat Plastik LDPE akan terhomogenisasi dengan baik sehingga semakin mudah untuk mengisi ruang dicetakan derts tidak terciptanya rongga-rongga pada papan partikel karena telah diisi oleh perekat plastik LDPE. Berdasarkan gambar 12 juga dapat dilihat bahwa semakin besar komposisi perekat plastic LDPE maka nilai kerapatan papan partikel akan semakin tinggi. Semakin tinggi persentase perekat yang digunakan , maka semakin tinggi sifat fisis dan mekanik pada papan partikel. Penambahan persentase perekat pada papan partikel akan menambah massa bahan baku sehingga nilai kerapatan yang diperoleh semakin tinggi. Kerapatan papan partikel memiliki pengaruh besar terhadap pengembangan tebal dan daya serap air pada papan partikel. Rendahnya nilai kerapatan menyebabkan tingginya nilai pengembangan tebal dan daya serap air papan. 


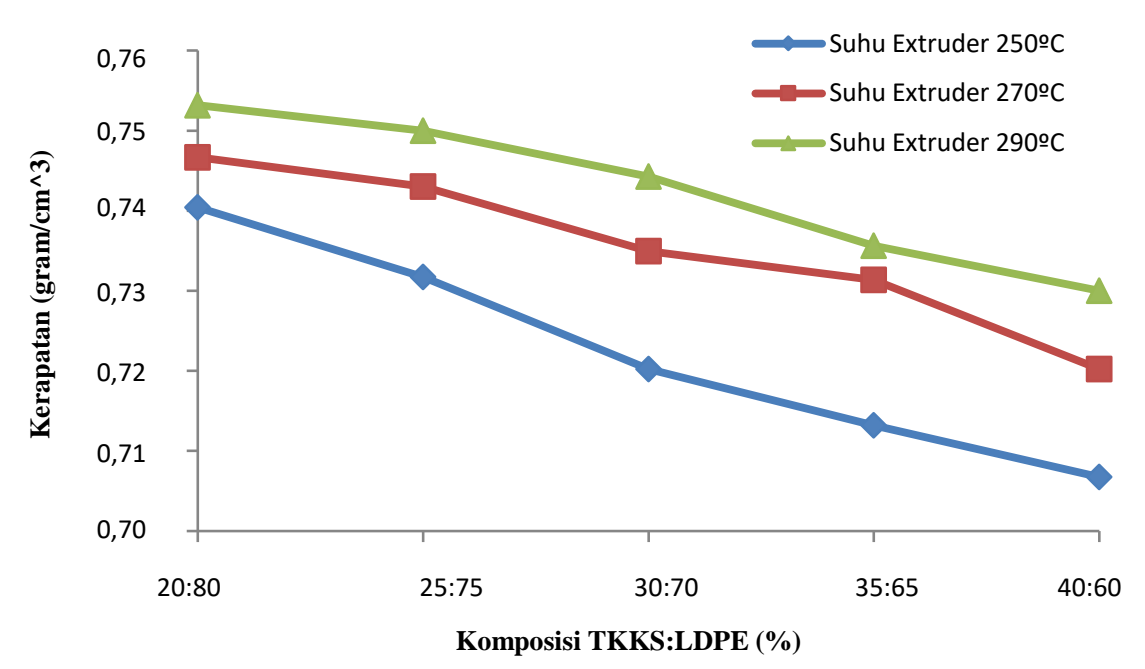

Gambar 12. Grafik Hubungan Antara Komposisi Bahan Baku dan Suhu Extruder Terhadap Kerapatan Papan Partikel

\subsection{Analisa Daya Serap Air}

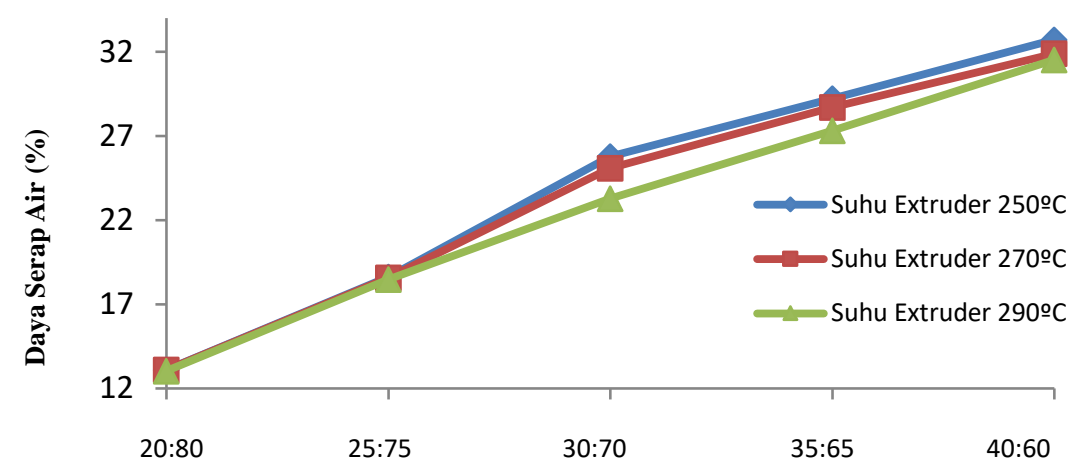

Komposisi TKKS:LDPE (\%)

Gambar 13. Grafik Hubungan Antara Komposisi Bahan Baku dan Suhu Extruder Terhadap Daya Serap Air Papan Partikel

Pada tabel 1 terlihat bahwa nilai daya serap air pada papan partikel mengalami peningkatan seiring bertambahnya persentase TKKS. Pada Gambar 13 yang dialurkan dari Tabel 1 dapat dilihat bahwa persentase daya serap air papan partikel tertinggi adalah pada papan partikel dengan komposisi TKKS:LDPE sebesar 40:60 dengan suhu extruder $250^{\circ} \mathrm{C}$. Sedangkan untuk persentase daya serap air papan partikel terendah yaitu pada papan partikel dengan komposisi TKKS:LDPE 20:80 dan suhu extruder sebesar $290^{\circ} \mathrm{C}$. Hal ini disebabkan karena pada saat proses perendaman, air akan mengisi rongga-rongga kosong pada papan partikel sehingga mengakibatkan air atau uap air akan mudah masuk kedalam papan partikel. Selulosa yang terkandung dalam papan partikel mampu menyerap air pada saat proses perendaman papan partikel dalam air dikarenakan adanya gaya absorbsi yang merupakan gaya tarik molekul air pada ikatan hidrogen yang terdapat dalam selulosa tersebut [4]. Sehingga semakin tinggi kerapatan papan partikel, maka ikatan antar partikel akan semakin kompak dan menyebabkan rongga udara dalam lembaran papan akan semakin kecil. Keadaan tersebut akan menyebabkan air menjadi sulit untuk mengisi rongga papan partikel tersebut semakin kecil daya serap air papan partikel, maka stabilitas papan tersebut semakin baik, demikian pula sebaliknya. Setelah selesai proses perendaman selama 24 jam, pada gambar 13 dapat dilihat bahwa pembahan persentase perekat berpengaruh terhadap daya serap yang dihasilkan. Hal ini disebabkan karena perekat plastik LDPE mengisi rongga-rongga yang kosong saat proses pencetakan papan partikel sehingga mencegah masuknya air kedalam rongga-rongga papan partikel. Hal ini berarti konsentrasi TKKS pada papan partikel berbanding lurus dengan daya serap air papan partikel dan berbanding terbalik dengan konsentrasi perekat plastic LDPE pada papan partikel. 


\subsection{Analisa Penambahan Tebal Setelah Perendaman}

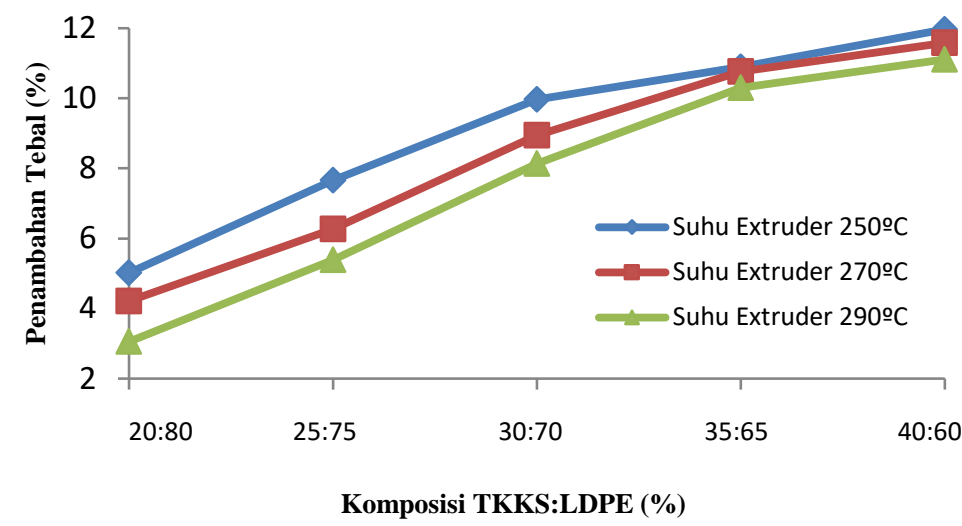

Gambar 14. Grafik Hubungan Antara Komposisi Bahan Baku dan Suhu Extruder Terhadap Penambahan Tebal Papan Partikel

Berdasarkan tabel 1 penambahan tebal setelah perendaman pada papan partikel yang dibuat secara keseluruhan telah memenuhi standar SNI 03-2105-2006 yaitu mensyaratkan nilai penambahan tebal pada papan papan partikel sebesar kurang dari 12\%. Pada gambar 14 yang dialurkan dari tabel 1 dapat dilihat bahwa untuk nilai persentase penambahan tebal papan partikel tertinggi sebesar $11,97 \%$ dengan perbandingan komposisi TKKS:LDPE yaitu 40:60 dengan Suhu Extruder $250^{\circ} \mathrm{C}$. Sedangkan untuk nilai persentase penambahan tebal papan partikel terendah sebesar 3,05\% yaitu pada perbandingan komposisi TKKS:LDPE sebesar 20:80 dengan Suhu Extruder $290^{\circ} \mathrm{C}$. Pertambahan tebal setelah perendaman seiring dengan pertambahan daya serap air papan serat mengakibatkan serat semakin terlapisi dengan baik oleh perekat sehingga kontak antara serat dan air menjadi lebih kecil. Perekat yang memasuki dinding serat dan kemudian mengeras dapat menciptakan hambatan fisik (physical barrier) sehingga menyebabkan penurunan penyerapan air yang menyebabkan penambahan tebal. Tingginya suhu extruder juga berpengaruh terhadap nilai penambahan tebal pada papan partikel. Dimana semakin rendah suhu extruder maka campuran TKKS dan Plastik LDPE akan semakin sulit untuk mengisi ruang didalam cetakan, sehingga semakin besar nilai penambahan tebal papan partikel. Keadaan ini disebabkan pada waktu perendaman, serat TKKS akan menyerap air sehingga serat-serat papan partikel akan kembali menjadi bentuk semula akibat hilangnya tekanan setelah perendaman. Penggunaan perekat dalam pembuatan papan partikel selain sebagai perekat juga berfungsi untuk mencegah air masuk kedalam papan. Semakin tinggi persentase penggunaan perekat, maka nilai penambahan tebal akan semakin rendah. Hal ini disebabkan karena semakin banyaknya perekat plastik yang digunakan maka ikatan antar partikel menjadi lebih kompak sehingga untuk air sulit untuk masuk kedalam papan partikel.

\section{KESIMPULAN}

Alat screw extruder yang dibuat mampu menghasilkan produk papan partikel berukuran 10 x $20 \mathrm{~cm}$ yang sesuai dengan SNI 03-2105-2006 yang dapat digunakan untuk papan pelapis dinding ruangan. Alat screw extruder yang dibuat mampu menghasilkan produk papan partikel yang sesuai dengan SNI 03-2105-2006 dengan nilai kerapatan maksimum $0,75 \mathrm{gr} / \mathrm{cm}^{3}$, persentase kadar air minimum $0,11 \%$, persentase pengembangan tebal papan partikel setelah perendaman 3,05\%, dan persentase daya serap air minimum 13,04\%. Pada pembuatan papan partikel dengan menggunakan alat screw extruder menghasilkan papan sesuai standar SNI 03-2105-2006. Dimana untuk nilai kerapatan tertinggi yaitu pada Suhu Extruder $290^{\circ} \mathrm{C}$ dengan perbandingan komposisi bahan TKKS:LDPE sebesar 20:80. Untuk nilai kadar air, daya serap air, dan penambahan tebal semakin kecil nialinya maka semakin baik dimana nilai minimum ini didapat pada Suhu Extruder $290^{\circ} \mathrm{C}$ dengan perbandingan komposisi bahan 20:80.

\section{DAFTAR PUSTAKA}

[1] Satito and Aryo, "Rancang Bangun Mesin Wood Plastic Composite Screw Extrussion Molding," in Prosiding Sentrinov, vol. 2, no.1, pp. 15-16, June.1, 2016.

[2] S. Maradu, "Perancangan unit Extruder Pada Mesin Extrusion Laminasi Fleksible Packaging, ” Jurnal Teknik Mesin ITI, vol. 2, no. 2, pp. 42-45, 2018, doi: 10.31543/jtm.v2i2.155 
[3] R. A. Muzata, "Pembuatan Particle Board dari Ampas Tebu (Saccharum officinarum) Berbasis Perekat Limbah Plastik Polipropilena dan Polistirena" Palembang: Jurusan Teknik Kimia, Politeknik Negeri Sriwijaya, 2015.

[4] J. G. Haygreen, and J. L. Bowyer, Hasil Hutan dan Ilmu Kayu. Suatu Pengantar. Hadikusumo S. A., Penerjemah: Prawirohatmodjo, S. Gadjah Mada University Press. Terjemahan dari: Forest Product and Wood Science, An Introduction. Yogyakarta, 1996.

[5] Darnoko, Potensi Pemanfaatan Limbah Lignoselulosa Kelapa Sawit Melalui Biokonversi, Medan: Pusat Penelitian Kelapa Sawit, 2001.

[6] D. Fitriani, J. Basmal, and B. S. B. Utomo, "Pengaruh Konsentrasi Maleat Anhidrida terhadap Mutu Papan Partikel yang Dibuat dari Limbah Padat Gracilaria sp. dan Polietilena sebagai Perekat,” Jurnal Pasca Panen dan Bioteknologi Kelautan dan Perikanan, vol. 6 no. 2, 2011, doi: 10.15578/jpbkp.v6i2.410

[7] S. Peacokk, Pengetahuan Bahan Teknik, Jakarta: Pradnya Paramita Jakarta, 2000.

[8] S. Zulnazri, and Nasrun, "Fabrikasi Material Komposit Plastik PP dan HDPE dengan Penguat Mikro Filler Tandan Kosong Kelapa Sawit dengan Proses Screw Extruder,” pp. 0-34, 2009. 